\title{
How can general practitioners reduce antibiotic prescribing in collaboration with their patients?
}

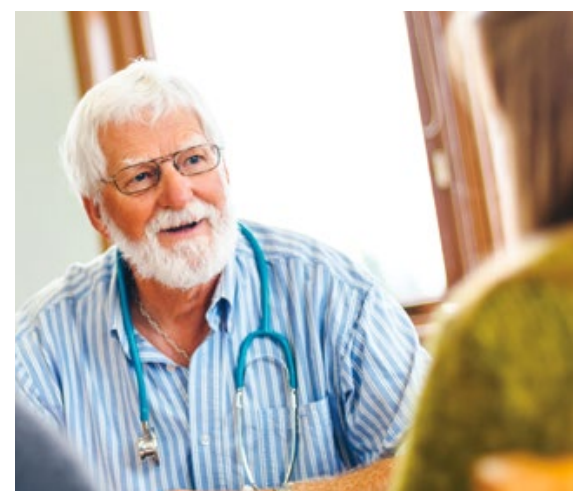

CPD

Chris Del Mar, Tammy Hoffmann, Mina Bakhit

\section{Background \\ Most antibiotics prescribed in primary care are for acute, and often self-limiting, conditions. Patients' expectations of needing antibiotics are an influential driver of general practitioners' (GPs') prescribing behaviour. Better managing patient expectations in consultations for acute infections may be important for reducing prescribing, particularly for self-limiting conditions.}

\section{Objective}

The aim of this article is to increase awareness about patients' beliefs and expectations about antibiotics for acute conditions and provide strategies and resources that GPs can use in collaboration with their patients for managing these expectations.

\section{Discussion}

Expectations of antibiotics may reflect a desire for symptomatic treatment, lack of awareness of other options or previous experience. Consultations for many acute conditions are particularly suited to shared decision making - it enables discussion about expectations and antibiotic benefits and harms and assists patients to make an informed decision. Delayed prescribing is another evidence-based strategy that can be used as part of shared decision making.
ANTIBIOTICS ARE PRESCRIBED MORE OFTEN IN PRIMARY CARE than other settings, with $42 \%$ of the Australian population being given at least one antibiotic prescription in 2017. ${ }^{1}$ Many of the conditions for which antibiotics are prescribed are self-limiting conditions, and antibiotics are often not needed, such as acute respiratory infections (ARIs) such as sore throat, acute bronchitis and acute otitis media (AOM). ${ }^{2-4}$ These conditions are highly prevalent in general practice, and antibiotics are overprescribed at rates 4-9 times as high as those recommended by Australian guidelines. ${ }^{5}$

General practitioners (GPs) are almost three times more likely to prescribe an antibiotic for their patients if they believe that the patients expect it. ${ }^{6}$ Perceived patient demand has been found to have a significant and independent effect on prescribing. ${ }^{7}$ There is often limited exploration and management of antibiotic expectations in consultations. ${ }^{8}$ Better managing patient expectations in consultations for acute infections may be important for reducing prescribing, particularly for self-limiting conditions.

\section{Patients' expectations of the need for antibiotics for common acute conditions}

Some patients erroneously believe that antibiotics are needed to treat any type of infection ${ }^{9}$ and that antibiotics are needed to kill the bacteria that is causing the infection. ${ }^{10} \mathrm{~A}$ commonly held belief is that an infection will not get better unless it is treated with antibiotics - this belief has been identified in multiple studies of patients with ARIs ${ }^{10}$ as well as those with other acute conditions, such as acute infective conjunctivitis. ${ }^{11}$

The benefits of antibiotics for acute infections are generally overestimated. A survey of Australian parents found that most participants overestimated the benefits of antibiotics for reducing the duration of respiratory infections. ${ }^{10}$ For example, participants believed that antibiotics provide a mean reduction in the duration of acute cough by five days, sore throat by 2.6 days and AOM by three days. This 
contrasts with estimates, from systematic reviews, of a reduction in illness duration from antibiotics of approximately half a day. ${ }^{10}$

Patients' expectations of or requests for antibiotics may reflect a desire for symptomatic treatment, lack of awareness of other options or previous experience of being provided with antibiotics. For example, in a study of patients with sore throat who asked for an antibiotic prescription, they were predominantly concerned about obtaining pain relief and believed that antibiotics were needed to relieve pain. ${ }^{12}$ Patients with conjunctivitis presented for antibiotic treatment because they were unaware of other potential options for managing the condition; they indicated that if they knew about the self-limiting nature of conjunctivitis, they would be willing to wait a few days before seeking medical advice. ${ }^{13}$ In women with lower urinary tract infection, their experience with current symptoms and/or previous experience with antibiotic treatment (either positive or negative) affects their request for an antibiotic or acceptance of a delayed antibiotic strategy. ${ }^{14}$ In a study of patients with a history of cellulitis, many were unaware of the risk of recurrence, expressed concerns about antibiotic side effects and were willing to accept a no-antibiotic prevention strategy. ${ }^{15}$

Poor awareness of the potential harms of antibiotics can also contribute to patients' desire for them. ${ }^{10}$ Many people have misperceptions about the nature of antibiotic resistance - believing that it is the body, not the bacteria, that becomes resistant to antibiotics - and a poor understanding of the consequences of resistance. ${ }^{16-18}$

Beyond the media, the largest patient education workforce moulding patients' expectations is GPs. But to do that well, more GPs need to be aware of their contribution to antibiotic resistance. Some clinicians do not perceive antibiotic resistance to be a problem, and of those who do, it is often perceived as not 'their problem'. ${ }^{19}$ In a study of Australian GPs, few recognised antibiotic prescribing as a contributing factor to the problem of resistance, and it was generally believed that individual-level antibiotic prescribing does not contribute to the problem of resistance when compared with hospital prescribing or antibiotic use in agriculture. ${ }^{20}$

\section{Strategies for dealing with patients' antibiotic expectations and/or requests \\ Deny antibiotics}

One strategy is to simply deny antibiotic prescription requests. However, there can be unwarranted problems associated with this. The GP-patient relationship is highly valued, ${ }^{21}$ and GPs are more willing to prescribe antibiotics if they feel that denying an antibiotic prescription will damage the relationship with their patient or lead to unnecessary confrontation. ${ }^{22}$ Some GPs believe that denying an antibiotic prescription may lead to their patient visiting another GP who is willing to prescribe it. Moreover, some GPs believe that denying antibiotics will not help to alter the patient's beliefs or antibiotic expectations for the next consultation. $^{22}$

One strategy that may help is for practices to make a public commitment to encouraging judicious antibiotic prescribing for acute infections. In practices randomised to displaying a poster-sized prescribing policy in the GPs' waiting room and/or examination room, there was a $20 \%$ absolute reduction in inappropriate antibiotic prescribing rate relative to the control group. ${ }^{23}$ Clear and consistent messaging in the mass media and public health campaigns about antibiotics not being needed for many infections can also help to improve public knowledge and expectations about antibiotics. NPS MedicineWise periodically runs media campaigns to achieve this. Media and public health campaigns are discussed further in the article in this issue by Glasziou et al. ${ }^{24}$

\section{Delayed prescribing}

Delayed prescribing can be used as a strategy when antibiotics are unlikely to be needed but a prescription is provided as a precaution. Delayed prescribing has been successfully used in primary care to reduce antibiotic prescribing for respiratory ${ }^{25}$ and urinary infections ${ }^{26}$ and bacterial conjunctivitis, ${ }^{27}$ and it is a safe strategy for most patients, including higher risk subgroups. ${ }^{28}$ In a recent systematic review and individual patient meta-analysis from nine randomised controlled trials and four observational studies, ${ }^{28}$ complications resulting in hospitalisation or death were lower with delayed prescribing when compared with no antibiotics (odds ratio [OR]: 0.62; 95\% confidence interval [CI]: $0.30,1.27)$ or immediate antibiotics (OR: 0.78; 95\% CI: 0.53, 1.13). Patients who received a delayed prescription were more satisfied than those who received no antibiotics at the end of the consultation, ${ }^{25}$ and with a significant reduction in consultation rates (OR: 0.72; 95\% CI: 0.60, 0.87). ${ }^{28}$ Thus, delayed prescribing may be a preferable strategy to simply denying antibiotics, especially when consulting with challenging patients. Delayed prescribing and safety netting is discussed further in the article in this issue by Magin et al. ${ }^{29}$

\section{Shared decision making}

Shared decision making is a strategy that shows promise in reducing antibiotic prescribing. It is an approach to communication and collaborative decision making in which clinicians and patients jointly discuss the available treatment options (including the option of 'no active treatment' when that is appropriate), the potential benefits and harms of each option and the patient's values, preferences and circumstances. ${ }^{30}$ Figure 1 explains the typical steps in a shared decision-making conversation, using the scenario of deciding about antibiotic use for acute sore throat.

In general practice, consultations for acute infections such as ARIs are particularly suited to shared decision making. This is because of misperceptions of the benefits and harms of antibiotics and the delicate balance between the marginal benefits of antibiotics and the possible individual and community harms from them. Shared decision making provides the opportunity to elicit and discuss expectations and correct any misperceptions about antibiotic benefits 


\section{Steps of a shared decision-making discussion}

Jennifer, aged 40 years, presents with a sore throat that she has had since yesterday, with no cough or any other associated respiratory symptoms. Examination is unremarkable except for a fever $\left(38^{\circ} \mathrm{C}\right)$, enlarged and red tonsils, and tender lymph nodes in her neck. She asks, 'Is there anything I can take, such as antibiotics, to help?'

\begin{tabular}{ll}
\hline & Details of the step \\
\hline $\begin{array}{l}\text { Let your patient know that } \\
\text { there is choice about the } \\
\text { next steps and a decision } \\
\text { to be made }\end{array}$ & $\begin{array}{l}\text { Invite the patient to participate with you in the decision making to the } \\
\text { extent that he/she desires and reassure any patient/caregiver who feels } \\
\text { overwhelmed or uncertain about their involvement. }\end{array}$ \\
\hline $\begin{array}{l}\text { Elicit the patient's } \\
\text { expectations and concerns } \\
\text { about the condition and its } \\
\text { management }\end{array}$ & $\begin{array}{l}\text { This can include previous experiences and treatments (eg antibiotics or } \\
\text { over-the-counter medications). Ask your patient if they have any fears or } \\
\text { concerns about the condition (eg a complication from it) or expectations } \\
\text { about how it is managed (eg antibiotics are necessary). This allows you } \\
\text { to detect and discuss any misperceptions. }\end{array}$ \\
\hline
\end{tabular}

List and explain the options Option 1: Wait and watch (this involves either no antibiotic prescription or providing a delayed prescription for antibiotics with an explanation regarding when to use it)

Option 2: Commence antibiotics immediately

Discuss the benefits and harms of each option

Describe the natural course of a sore throat infection and explain that typically it will resolve within 4-7 days without taking antibiotics.

Explain that patients who take antibiotics have a sore throat, on average, for only about 16 hours less than people who do not, and that antibiotic use carries the risk of side effects (eg vomiting, diarrhoea and rash) and of antibiotic resistance (and provide a simple explanation about what this is and the implication of this).

The benefit can also be explained using natural frequencies (that is, how many out of 100 people get better, with and without antibiotics).

Explain that there is uncertainty about whether the patient will be one of the people who will be helped or harmed by antibiotics. A decision aid can be shown to your patient during this step, or earlier, to facilitate the discussion.

Explain to your patient that symptoms, such as pain and fever, can be treated with over-the-counter medicines. They can be used with either option.

If you have concerns about the patient's comprehension of any of this, ask them to explain in their own words what the options are and their main pros and cons.

Weigh up the options

Encourage your patient to weigh up the benefits and harms of the options and talk about what matters most to them when considering their preferences, values and circumstances. What matters most to your patient could be the shortened recovery time or the harms that can come from taking medication, including the cost or remembering to take them.

Check the patient's

Explore if your patient is ready to make a decision, would like additional

readiness to decide information or has any questions. For some decisions, your patient may also choose to discuss the options with family or friends before deciding.

Reach a shared decision

Decide with your patient about the next steps. Provide 'safety-netting' information about when to start antibiotics (if delayed prescription option chosen) or re-consult, such as if they develop the following symptoms:

- very drowsy

- persistent fever and/or increase in pain

- drooling or swallowing problems

- fast, noisy or difficult breathing, or shortness of breath

- a rash that does not fade when the skin is pressed

- unusual skin colour around the lips (pale or blue)

- pain in the arms and/or legs

- cold or discoloured hands and/or feet with a warm body.
Example of possible phrasing, with relevance to this scenario

'Waiting for the sore throat to get better by itself is one option. Another option is to take antibiotics.'

'We know from good research that of 100 patients like yourself with sore throat who do not take antibiotics, 28 will feel better and have no sore throat at three days. Out of 100 patients who do take antibiotics, 34 will feel better at about three days of taking them. So, about six more will be better at three days.'

'We can't know whether you will be one of the six people who benefit or not.'

'We also need to consider the possible harms of taking antibiotics ...'

'What matters most to you?'

Figure 1. Steps in a shared decision-making discussion, with examples for the scenario of deciding about antibiotic use for acute sore throat 
and harms and the infection. It enables GPs and patients to discuss the benefits and harms of using and not using antibiotics and jointly decide on the most appropriate option for that person at that time.

In a Cochrane review that examined the effect of interventions that facilitated shared decision making in primary care consultations with patients with ARIs, ${ }^{31}$ the interventions significantly reduced antibiotic prescribing at or immediately after the index consultation by $47 \%$, compared with $29 \%$ in the usual care group (risk ratio $0.61 ; 95 \% \mathrm{CI}$ : 0.55, 0.68; $P<0.001)$. The reduction in antibiotic prescribing was not associated with an increase in re-consultation rates or decrease in patient satisfaction. ${ }^{31}$

Delayed prescribing can be used in conjunction with shared decision making for self-limiting conditions such as ARIs, uncomplicated urinary tract infections, conjunctivitis and skin infections such as non-bullous impetigo..$^{25,27,32,33}$ If the option of 'wait and see'/no immediate antibiotics is chosen, patients and GPs may sometimes feel more comfortable if an 'in case' antibiotic prescription is provided, along with safety-netting information about when to use it or re-consult. As shown in Figure 1, as part of this option, it is important that patients are told how long it would normally take for the infection to resolve if antibiotics are not used. Public campaigns such as Choosing Wisely Australia encourage patients to ask their clinicians "what happens if I do nothing?" as part of the decision-making process.

Shared decision making can be facilitated by using decision support tools such as patient decision aids. These tools provide evidence-based information about the health condition, treatment options (including the option of 'wait and see' when appropriate), the benefits and harms of each option and the likelihood or size of the benefits and harms. When aids are used in a consultation, higher levels of shared decision making and discussion of benefits and harms are observed. ${ }^{34}$ However, the use of aids does not guarantee that shared decision making will occur, nor are they essential for shared decision making to happen - it is the nature and content of the conversation that is important. ${ }^{30}$

Shared decision making can be more challenging, but is still possible, with people who have low health literacy. Systematic reviews ${ }^{35,36}$ have shown that the comprehension of health information among patients with low health literacy can be improved by reducing medical jargon, presenting essential information first, tailoring the amount and speed of information provided and using easy-toread tools. These principles also apply when engaging patients with low health literacy in shared decision making.

Table 1 lists some of the tools that can be used in consultations for acute infections, including patient decision aids, guidance boxes, ARI action plans that list

\section{Table 1. Resources to assist with shared decision making and/or patient education for common acute infections}

\begin{tabular}{|c|c|c|c|c|}
\hline \multirow[b]{2}{*}{ Indication } & \multicolumn{4}{|c|}{ Available resources (and where to locate them) } \\
\hline & $\begin{array}{l}\text { Patient } \\
\text { decision aid }\end{array}$ & $\begin{array}{l}\text { NPS MedicineWise } \\
\text { Respiratory tract } \\
\text { infection action plan* }\end{array}$ & $\begin{array}{l}\text { Guidance (on } \\
\text { shared decision } \\
\text { making) box }\end{array}$ & $\begin{array}{l}\text { Patient education } \\
\text { materials (printed } \\
\text { or online) }\end{array}$ \\
\hline Acute rhinosinusitis & $\checkmark^{\dagger}$ & $\checkmark$ & $\checkmark \ddagger$ & $\checkmark \S, \|, \#$ \\
\hline Acute otitis media & $\checkmark^{* *}$ & $\checkmark$ & $\checkmark \ddagger$ & \\
\hline Acute sore throat & $\checkmark^{* *}$ & $\checkmark$ & $\checkmark \ddagger$ & $\sqrt{ } \S_{\text {,ll, \# }}$ \\
\hline Acute bronchitis & $\checkmark^{* *}$ & $\checkmark$ & $\checkmark^{\ddagger}$ & $\checkmark{ }^{\S, \|, \#}$ \\
\hline $\begin{array}{l}\text { Uncomplicated urinary tract } \\
\text { infections in non-pregnant women }\end{array}$ & & & & $\checkmark^{\#, t \dagger, \ddagger \ddagger}$ \\
\hline Acne & $\checkmark \S \S$ & & $\checkmark^{\text {IIII }}$ & $\checkmark^{\#}$ \\
\hline Viral upper respiratory tract infection & & $\checkmark$ & & $\checkmark^{\#}$ \\
\hline 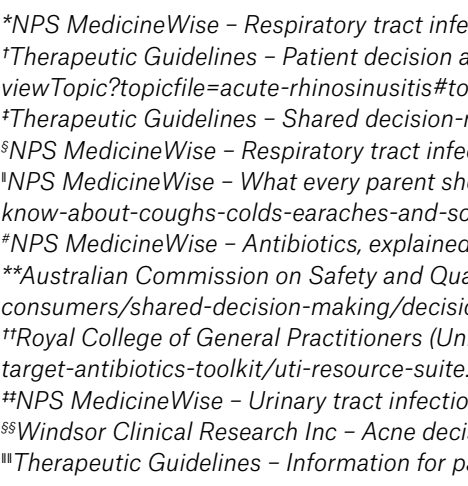 & $\begin{array}{l}\text { ion action plan, } \\
\text { in Antibiotic: Ea } \\
\text { dle } 280 \\
\text { king boxes, in Ar } \\
\text { ons, www.nps.or } \\
\text { ld know about co } \\
\text {-throats } \\
\text { vww.nps.org.au/c } \\
\text { y in Health Care } \\
\text {-support-tools-p } \\
\text { d Kingdom) - Ur } \\
\text { px } \\
\text { (UTIs) explained } \\
\text { n aid, www.infor } \\
\text { ents with acne, ir }\end{array}$ & $\begin{array}{l}\text { ps.org.au/professionals/redu } \\
\text { eand throat infections (Acut } \\
\text { ic: Ear, nose and throat infec } \\
\text { onsumers/respiratory-tract- } \\
\text { colds, earaches and sore thr } \\
\text { ners/antibiotics-explained } \\
\text { ision support tools for consu } \\
\text { tract infection resource suite } \\
\text { v.nps.org.au/consumers/urin } \\
\text { decisions.org/acnepda_introc } \\
\text { natology: Acne, https://tgldc }\end{array}$ & $\begin{array}{l}\text { ibiotic-resistance\#res } \\
\text { husitis), https://tgldcc } \\
\text { vw.tg.org.au } \\
\text { s-rtis-nose-throat-an } \\
\text { w.nps.org.au/consum } \\
\text { ww.safetyandquality.g } \\
\text { gp.org.uk/clinical-ano } \\
\text {-infections-utis } \\
\text { hp } \\
\text {.au/viewTopic?topicf }\end{array}$ & $\begin{array}{l}\text { ps } \\
\text { prg.au/ } \\
\text { vhat-every-parent-should- } \\
\text { arch/resources/toolkits/amr/ } \\
\text { ane\#toc_die639 }\end{array}$ \\
\hline
\end{tabular}


ways to manage symptoms, and patient education materials that can sometimes be used in conjunction with other resources or on their own (eg a discussion about a simple common cold is unlikely to require a shared decision making process).

\section{Conclusion}

Patients' expectations of the need and requests for antibiotics for acute conditions are strong influencers of GPs' prescribing behaviour. Simply denying antibiotics is one strategy; however, it can have unwanted effects on the GP-patient relationship and does not assist with modifying patients' beliefs and expectations about antibiotics for future conditions. Shared decision making is an approach to communication that involves elicitation and discussion of patients' antibiotic expectations, the benefits and harms of using and not using antibiotics, and alternative options. It involves patients and GPs reaching a collaborative decision about whether to use antibiotics, can also incorporate the strategy of delayed prescribing and may be an important way to reduce antibiotic prescribing.

\section{Authors}

Chris Del Mar MA, MB BChir, FRACGP, FAFPHM, MD, Professor of Public Health, Institute for EvidenceBased Healthcare, Faculty of Health Sciences and Medicine, Bond University, Gold Coast, Qld Tammy Hoffmann PhD, FAAHMS, Professor of Clinical Epidemiology, Institute for Evidence-Based Healthcare, Faculty of Health Sciences and Medicine, Bond University, Gold Coast, Qld

Mina Bakhit PhD, MBBCh, Postdoctoral Research Fellow, Institute for Evidence-Based Healthcare, Faculty of Health Sciences and Medicine, Bond University, Gold Coast, Qld

Competing interests: None.

Funding: None.

Provenance and peer review: Commissioned, externally peer reviewed.

\section{Correspondence to:}

cdelmar@bond.edu.au

\section{References}

1. Australian Commission on Safety Quality in Health Care. AURA 2019: Third Australian report on antimicrobial use and resistance in human health. Sydney, NSW: ACSQHC, 2019.

2. Smith SM, Fahey T, Smucny J, Becker LA. Antibiotics for acute bronchitis. Cochrane Database Syst Rev 2017;6(6):CD000245. doi: 10.1002/14651858.CD000245.pub4.

3. Spinks A, Glasziou PP, Del Mar CB. Antibiotics for sore throat. Cochrane Database Syst Rev 2013;2013(11):CD000023. doi: 10.1002/14651858. CD000023.pub4.
4. Venekamp RP, Sanders SL, Glasziou PP, Del Mar CB, Rovers MM. Antibiotics for acute otitis media in children. Cochrane Database Syst Rev 2015;2015(6):CD000219. doi: 10.1002/14651858.CD000219.pub4.

5. McCullough AR, Pollack AJ, Plejdrup Hansen M, et al. Antibiotics for acute respiratory infections in general practice: Comparison of prescribing rates with guideline recommendations. Med J Aust 2017;207(2):6569. doi: 10.5694/mja16.01042.

6. Little P, Dorward M, Warner G, Stephens K, Senior J, Moore M. Importance of patient pressure and perceived pressure and perceived medical need for investigations, referral, and prescribing in primary care: Nested observational study. BMJ 2004;328(7437):444. doi: 10.1136/ bmj.38013.644086.7C.

7. Coenen S, Michiels B, Renard D, Denekens J, Van Royen P. Antibiotic prescribing for acute cough: The effect of perceived patient demand. Br J Gen Pract 2006;56(524):183-90.

8. Mustafa M, Wood F, Butler CC, Elwyn G. Managing expectations of antibiotics for upper respiratory tract infections: A qualitative study. Ann Fam Med 2014;12(1):29-36. doi: 10.1370/ afm.1583.

9. Boiko O, Gulliford MC, Burgess C. Revisiting patient expectations and experiences of antibiotics in an era of antimicrobial resistance: Qualitative study. Health Expect 2020;23(5):1250-58. doi: 10.1111/hex.13102

10. Coxeter PD, Mar CD, Hoffmann TC. Parents' expectations and experiences of antibiotics for acute respiratory infections in primary care. Ann Fam Med 2017;15(2):149-54. doi: 10.1370/ afm.2040.

11. Rose PW, Ziebland S, Harnden A, Mayon-White R, Mant D; Oxford Childhood Infection Study group (OXCIS). Why do general practitioners prescribe antibiotics for acute infective conjunctivitis in children? Qualitative interviews with GPs and a questionnaire survey of parents and teachers. Fam Pract 2006;23(2):226-32. doi: 10.1093/ fampra/cmi101.

12. van Driel ML, De Sutter A, Deveugele M, et al. Are sore throat patients who hope for antibiotics actually asking for pain relief? Ann Fam Med 2006;4(6):494-99. doi: 10.1370/afm.609.

13. Everitt $H$, Kumar S, Little P. A qualitative study of patients' perceptions of acute infective conjunctivitis. Br J Gen Pract 2003;53(486):36-41.

14. Leydon GM, Turner S, Smith H, Little P; UTIS team. Women's views about management and cause of urinary tract infection: Qualitative interview study. BMJ 2010;340:c279. doi: 10.1136/ bmj.c279.

15. Teasdale EJ, Lalonde A, Muller I, et al. Patients' understanding of cellulitis and views about how best to prevent recurrent episodes: Mixedmethods study in primary and secondary care. Br J Dermatol 2019;180(4):810-20. doi: 10.1111/ bjd. 17445 .

16. Bakhit M, Del Mar C, Gibson E, Hoffmann T. Exploring patients' understanding of antibiotic resistance and how this may influence attitudes towards antibiotic use for acute respiratory infections: A qualitative study in Australian general practice. BMJ Open 2019;9(3):e026735. doi: 10.1136/bmjopen-2018-026735.

17. McCullough AR, Parekh S, Rathbone J, Del Mar CB, Hoffmann TC. A systematic review of the public's knowledge and beliefs about antibiotic resistance. J Antimicrob Chemother 2016;71(1):27-33. doi: 10.1093/jac/dkv310.

18. Bakhit M, Hoffmann T, Scott AM, Beller E, Rathbone J, Del Mar C. Resistance decay in individuals after antibiotic exposure in primary care: A systematic review and meta-analysis. BMC Med 2018;16(1):126. doi: 10.1186/s12916-018-1109-4.

19. McCullough AR, Rathbone J, Parekh S, Hoffmann TC, Del Mar CB. Not in my backyard: A systematic review of clinicians' knowledge and beliefs about antibiotic resistance. J Antimicrob Chemother 2015;70(9):2465-73. doi: 10.1093/jac/ dkv164.

20. Fletcher-Lartey S, Yee M, Gaarslev C, Khan R. Why do general practitioners prescribe antibiotics for upper respiratory tract infections to meet patient expectations: A mixed methods study. BMJ Open 2016;6(10):e012244. doi: 10.1136/bmjopen-2016012244.

21. Kearley KE, Freeman GK, Heath A. An exploration of the value of the personal doctor-patient relationship in general practice. $\mathrm{Br} J$ Gen Pract 2001;51(470):712-18.

22. Butler CC, Rollnick S, Pill R, Maggs-Rapport F, Stott N. Understanding the culture of prescribing: Qualitative study of general practitioners' and patients' perceptions of antibiotics for sore throats. BMJ 1998;317(7159):637-42. doi: 10.1136/ bmj.317.7159.637.

23. Meeker D, Knight TK, Friedberg MW, et al. Nudging guideline-concordant antibiotic prescribing: A randomized clinical trial. JAMA Intern Med 2014;174(3):425-31. doi: 10.1001/ jamainternmed.2013.14191.

24. Glasziou P, Dartnell J, Biezen R, Morgan M, Manski-Nankervis JA. Antibiotic stewardship: A review of successful, evidence-based primary care strategies. Aust J Gen Pract 2022;51(1-2):15-20.

25. Spurling GK, Del Mar CB, Dooley L, Foxlee R, Farley R. Delayed antibiotic prescriptions for respiratory infections. Cochrane Database Syst Rev 2017;9(9):CD004417. doi: 10.1002/14651858. CD004417.pub5.

26. Little P, Moore MV, Turner S, et al. Effectiveness of five different approaches in management of urinary tract infection: Randomised controlled trial. BMJ 2010;340:c199. doi: 10.1136/bmj.c199.

27. Everitt HA, Little PS, Smith PW. A randomised controlled trial of management strategies for acute infective conjunctivitis in general practice. BMJ 2006;333(7563):321. doi: 10.1136/ bmj.38891.551088.7C.

28. Stuart B, Hounkpatin H, Becque T, et al. Delayed antibiotic prescribing for respiratory tract infections: Individual patient data meta-analysis. BMJ 2021;373:n808. doi: 10.1136/bmj.n808.

29. Magin P, Davey AR, Davis J. Evidence-based strategies for better antibiotic prescribing. Aust J Gen Pract 2022;51(1-2):21-24.

30. Hoffmann TC, Légaré F, Simmons MB, et al. Shared decision making: What do clinicians need to know and why should they bother? Med J Aust 2014;201(1):35-39. doi: 10.5694/mja14.00002.

31. Coxeter P, Del Mar CB, McGregor L, Beller EM Hoffmann TC. Interventions to facilitate shared decision making to address antibiotic use for acute respiratory infections in primary care. Cochrane Database Syst Rev 2015;2015(11):CD010907. doi: 10.1002/14651858.CD010907.pub2.

32. Hoffmann TC, Bakhit M, Del Mar C Uncomplicated urinary tract infection in women. BMJ 2021;372:n725. doi: 10.1136/bmj.n725.

33. Hoffmann TC, Peiris R, Glasziou P, Cleo G, Mar CD. Natural history of non-bullous impetigo: A systematic review of time to resolution or improvement without antibiotic treatment. $\mathrm{Br} J$ Gen Pract 2021;71(704):e237-42. doi: 10.3399/ bjgp20X714149.

34. Bakhit M, Del Mar C, Gibson E, Hoffmann T. Shared decision making and antibiotic benefit- 
harm conversations: An observational study of consultations between general practitioners and patients with acute respiratory infections. BMC Fam Pract 2018;19(1):165. doi: 10.1186/s12875-0180854-y.

35. Sheridan SL, Halpern DJ, Viera AJ, Berkman ND, Donahue KE, Crotty K. Interventions for individuals with low health literacy: A systematic review. J Health Commun 2011;16 Suppl 3:30-54. doi: 10.1080/10810730.2011.604391.

36. Visscher BB, Steunenberg B, Heijmans M, et al. Evidence on the effectiveness of health literacy interventions in the EU: A systematic review. BMC Public Health 2018;18(1):1414. doi: 10.1186/s12889018-6331-7. 